\title{
TRAF6 deficiency promotes TNF-induced cell death through inactivation of GSK3 $\beta$
}

\author{
K Yoon ${ }^{1}$, EJ Jung ${ }^{1}$, SR Lee', J Kim ${ }^{1,2}$, Y Choi ${ }^{3}$ and SY Lee ${ }^{1,2}$
}

\begin{abstract}
TNF receptor-associated factor 6 (TRAF6) plays a key role in the regulation of innate immune responses by mediating signals from both TNF receptors (TNFRs) and interleukin-1 receptors (IL-1Rs)/Toll-like receptors (TLRs). Here, we define a new role for TRAF6 in antagonizing cell death during TNF signaling. In TRAF6-deficient $3 \mathrm{~T}^{3}\left(\mathrm{~T}^{-l-}\right.$ 3T3) cells, TNF stimulation leads to the accumulation of reactive oxygen species (ROS), which in turn results in prolonged c-Jun N-terminal kinase (JNK) activation and accelerated cell death. Furthermore, TNF-induced p65/RelA phosphorylation as well as transcriptional activity of nuclear factor- $\kappa \mathrm{B}\left(\mathrm{NF}-\kappa_{\mathrm{B}}\right)$ was significantly downregulated in $\mathrm{T}^{-1-}$ 3T3 cells. Interestingly, TRAF6 deficiency leads to constitutive phosphorylation and inactivation of glycogen synthase kinase $3 \beta$ (GSK3 $\beta$ ). Restoration of GSK3 $\beta$ activity through exogenous expression of a GSK3 $\beta$ constitutive active form rescued cell death in TRAF6-null 3T3 cells. These data suggest a role for TRAF6 in the maintenance of cell survival by regulating GSK3 $\beta$ activity in TNF signaling.
\end{abstract}

Cell Death and Differentiation (2008) 15, 730-738; doi:10.1038/sj.cdd.4402304; published online 18 January 2008

Homeostasis in mammalian cells is dependent on the continuous integration of cell survival and cell death signals from the extracellular environment. ${ }^{1} \quad$ TNF signaling network provides a paradigm for elucidating the signaling pathways utilized by other TNF ligand superfamily members and their receptors. ${ }^{2}$ An interesting feature of the TNF signaling network is the extensive cross-talk between cell survival and death signaling pathways that emanate from TNF receptor 1 (TNFR1). ${ }^{3}$

Regulation of TNF signaling is complex and is achieved through multiple steps. The initial step in TNF signaling involves the binding of the TNF trimer to the extracellular domain of TNFR1 leading to the formation TNFR1 complex containing TRADD, TNF receptor-associated factor 2 (TRAF2), and RIP, which subsequently results in the activation of nuclear factor- $\kappa \mathrm{B}$ (NF- $\kappa \mathrm{B})$ and c-Jun $\mathrm{N}$-terminal kinase $(\mathrm{JNK}){ }^{4-6}$ It is well established that activation of NF- $\kappa \mathrm{B}$ serves as a primary mechanism in protecting cells from death stimuli such as TNF., ${ }^{1,3}$ For instance, in the absence of NF- $\kappa$ B activity, cellular susceptibility to TNF-induced toxicity increases, whereas forced activation of NF- $\kappa$ B protects from cell death.

The involvement of JNK in TNF-induced cell death represents another level of control in TNF signaling. ${ }^{7}$ It was demonstrated that reactive oxygen species (ROS), whose production is induced by TNF, are responsible for prolonged JNK activation. ${ }^{8}$ More recent investigations have revealed that the proapoptotic JNK signaling pathway is inhibited by NF- $\kappa \mathrm{B}$ signaling. ${ }^{9,10}$ These results collectively suggested that the cross-talk of NF- $\kappa \mathrm{B}$ with other signaling pathways is critical for deciding the cellular fate, notably cell survival or death under oxidative conditions. Although the molecular mechanisms, including the role of modulators of TNF signaling, have been largely elucidated, the nature of the cross-talk between TNF-induced cell death signaling and JNK signaling pathways, most likely via regulation of NF- $\kappa$ B activation, is still unclear.

Tumor necrosis factor receptor-associated factors (TRAFs) have been identified as signaling intermediates for TNFR superfamily members and are known to activate transcription factors, including NF- $\kappa \mathrm{B}$, NFAT, and AP-1. ${ }^{11,12}$ The six known mammalian TRAFs (TRAF1TRAF6) were classified as a gene family on the basis of a conserved TRAF domain at the $C$ terminus, which mediates self-association and interactions with receptors and other signaling proteins. ${ }^{12}$ TRAF family proteins also feature an $\mathrm{N}$-terminal zinc-binding domain that is believed to mediate the activation of several mitogenactivated protein kinase (MAPK) kinase kinases (MAPKKKs), including TAK1, ASK1 and NIK. ${ }^{13,14}$ Recently, a novel member of the TRAF family, TRAF7, has been designated based on the homology of the RING and zinc finger domains with other TRAF proteins. ${ }^{15}$

\footnotetext{
Author's contributions: K Yoon: designed research, performed research, collected data, and analyzed data. EJ Jung and SR Lee: performed research and collected data. J Kim: interpreted data and drafted the manuscript. Y Choi: contributed new reagents and interpreted data. SY Lee: designed research, analyzed data, interpreted data, and drafted the manuscript.

${ }^{1}$ Division of Life and Pharmaceutical Sciences, Center for Cell Signaling \& Drug Discovery Research, College of Natural Sciences, Ewha Womans University, Seoul, Korea; ${ }^{2}$ Department of Life Science, College of Natural Sciences, Ewha Womans University, Seoul, Korea and ${ }^{3}$ Department of Pathology \& Laboratory Medicine, Abramson Family Cancer Research Institute, University of Pennsylvania School of Medicine, Philadelphia, PA, USA

Corresponding author: SY Lee, Division of Life and Pharmaceutical Sciences, Center for Cell Signaling \& Drug Discovery Research, Department of Life Science, College of Natural Sciences, Ewha Womans University, Seoul 120-750, Korea. Tel: + 8223277 3770; Fax: + 8223277 3760; E-mail: leesy@ewha.ac.kr Keywords: GSK3 $\beta$; JNK; NF- $\kappa$ B; ROS; TRAF6

Abbreviations: TRAF6, tumor necrosis factor receptor-associated factor 6; NF- $\kappa \mathrm{B}$, nuclear factor- $\kappa \mathrm{B}$; JNK, c-Jun N-terminal kinase; ROS, reactive oxygen species; GSK3 $\beta$, glycogen synthase kinase $3 \beta$; MAP kinase, mitogen-activated protein kinase

Received 04.7.07; revised 21.11.07; accepted 06.12.07; Edited by V De Laurenzi; published online 18.1.08
} 
A unique feature of TRAF6 is that, unlike other TRAFs, it also participates in interleukin-1 receptor (IL-1R)/ Toll-like receptor (TLR) superfamily signaling. ${ }^{16}$ In this pathway, TLR-MyD88 association activates IRAK which in turn leads to TRAF6-mediated activation of the NF- $\kappa \mathrm{B}$ and MAPK cascades, ${ }^{17}$ thereby playing an essential role in innate immune responses. A previous study has also shown that TRAF6 deficiency resulted in defects in IL-1, CD40, and LPS signaling. ${ }^{18}$ It is therefore possible that TRAF6 functions at the central point where signals induced by the TLR and TNFR families converge. A recently published study showed that TRAF6-deficient fibroblast is sensitive to TNF in the presence of actinomycin D. ${ }^{19}$ However, the molecular mechanisms through which TRAF6 regulates TNF signaling are completely unknown. To examine the role of TRAF6 in TNF-induced signaling, we characterized the response of TRAF6-deficient 3T3 (T6 ${ }^{-1-}$ 3T3) cells to TNF. We describe a novel role for TRAF 6 in TNF-induced NF- $\kappa$ B activation and protection from cell death

\section{Results}

TNF induces cell death through ROS accumulation in T6 $^{-1-}$ 3T3 cells. TRAF2 and TRAF6 have been shown to be involved in NF- $\kappa \mathrm{B}$ and MAP kinase activation mediated by TNFR1 and IL-1R/TLR, respectively. ${ }^{2,17}$ To explore whether TRAF6 has a role in TNF signaling, we compared the time course of cell death in $\mathrm{T} 6^{-1-}$ cells, $\mathrm{T} 2^{-1-}$ cells and wild-type (WT) 3T3 cells that were characterized by western blotting (Figure 1a). As reported previously, ${ }^{6,20} \mathrm{~T}^{-/-}$cells were rapidly killed by TNF (Figure 1b). Unexpectedly, $\mathrm{T6}^{-1-}$ cells also showed a heightened sensitivity to TNF (Figure1b and Supplementary Figure 1), the level of which was comparable to that in $\mathrm{T}^{-1-}$ cells. In the presence of cycloheximide, which prevents de novo synthesis of NF- $\kappa$ B-dependent cytoprotective proteins, the susceptibility of $\mathrm{T6}^{-1-}$ cells to TNF significantly increased in a manner similar to what was seen in $\mathrm{T}^{-1-}$ 3T3 cells (Figure 1c). The cell death in both cases was accompanied by caspase 3 cleavage (Figure $1 \mathrm{~d}$ ). When $\mathrm{T}^{-1-}$ cells were reconstituted with TRAF6 full-length gene, cells

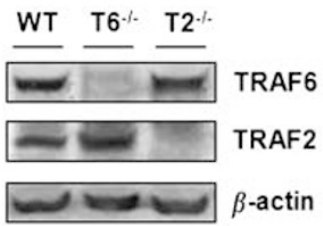

b

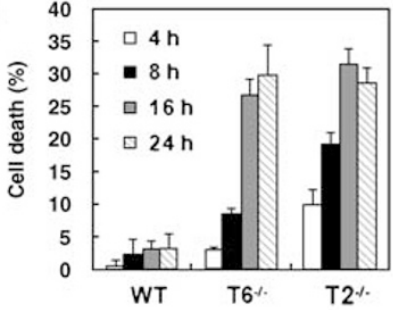

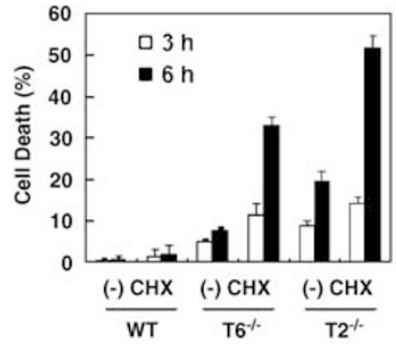

d

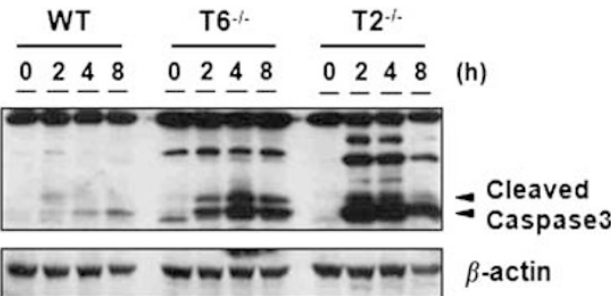

e

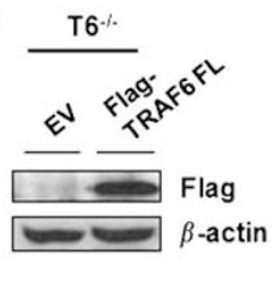

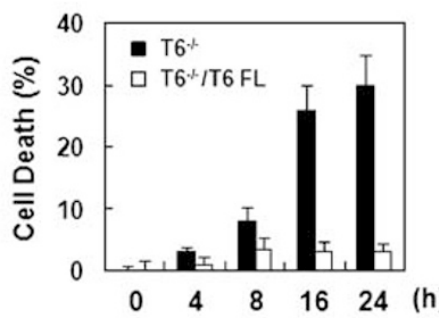

$\mathbf{f}$

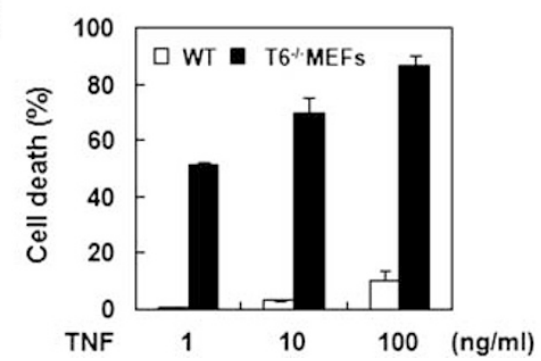

g

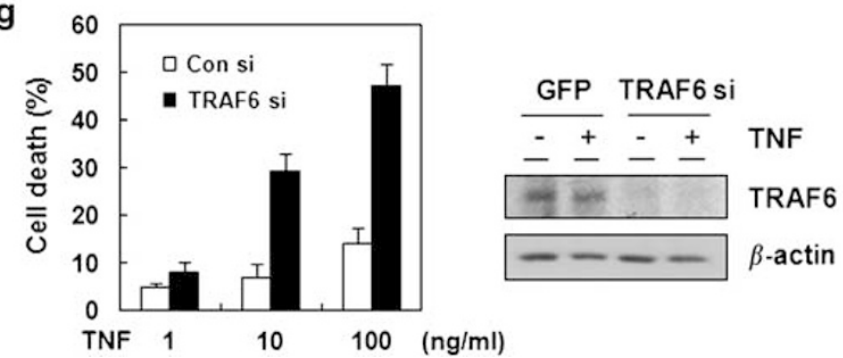

Figure 1 TNF-induced cell death in $\mathrm{T}^{-1-} 3 \mathrm{~T} 3 \mathrm{cells}$. (a) Characterization of $\mathrm{T6}^{-1-}$ and $\mathrm{T}^{-1-} 3 \mathrm{~T} 3 \mathrm{cells}$. Western blotting confirmed the absence of TRAF2 and TRAF6 proteins in their respective deficient $3 \mathrm{~T} 3$ cells. (b) TNF alone induced cell death in $\mathrm{T6}^{-l-}$ and $\mathrm{T}^{-l-} 3 \mathrm{~T} 3$ cells. Cells were incubated with TNF ( $30 \mathrm{ng} / \mathrm{ml}$ ) for the indicated times, harvested, stained with propidium iodide, and analyzed by flow cytometry to determine the extent of cell death. Dead cells were plotted as percentages over unstimulated controls. (c) As in (b), except that cells were incubated with TNF in combination with cycloheximide $(0.25 \mu \mathrm{g} / \mathrm{ml})$ for the indicated times. (d) Cells were stimulated as in (b). Cleaved caspase 3 was detected by anti-caspase 3 antibody. (e) Stable expression of Flag-tagged TRAF6 can rescue T6 ${ }^{-1}-3 T 3$ cells from TNF-induced cell death. Left, restoration of Flag-TRAF6 protein expression in its reconstituted cells; right, TRAF6 reconstitution restored the resistance of T6 ${ }^{-1-} 3 T 3$ cells to TNF. (f) As in (c), except that WT and T6 ${ }^{-1-}$ MEFs were incubated for $16 \mathrm{~h}$. (g) Left, HAECs were transfected with human TRAF6 siRNA or GFP siRNA (control siRNA). At $48 \mathrm{~h}$ post transfection, cells were stimulated with the indicated dose of TNF and cycloheximide (1 $\mu \mathrm{g} / \mathrm{ml})$ for $16 \mathrm{~h}$. Right, knock down of TRAF6 gene was confirmed by western blot analysis. The data (b, $\mathbf{c}, \mathbf{e}-\mathbf{g}$ ) indicate means \pm S.D. of four independent experiments 
a

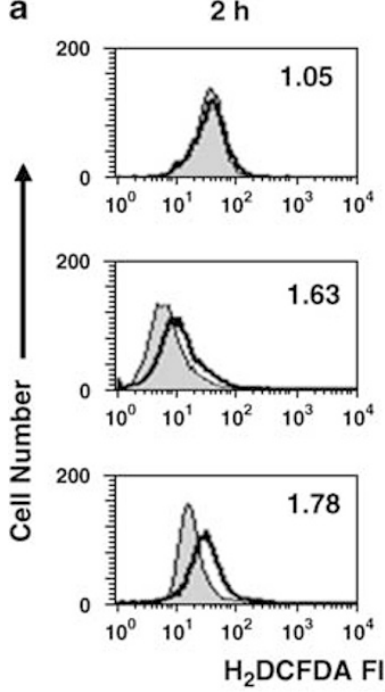

b

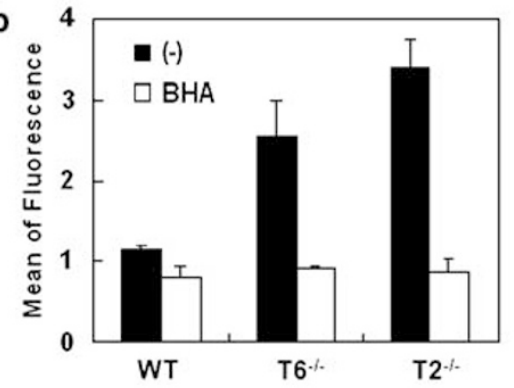

$4 \mathrm{~h}$
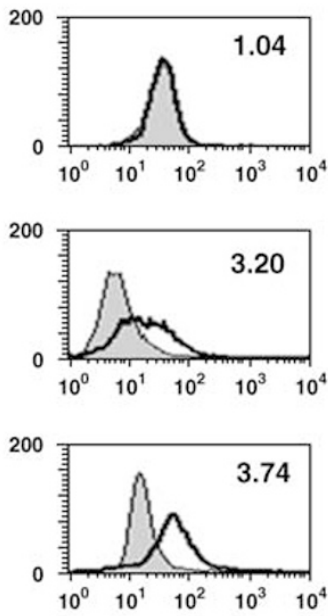

$8 \mathrm{~h}$
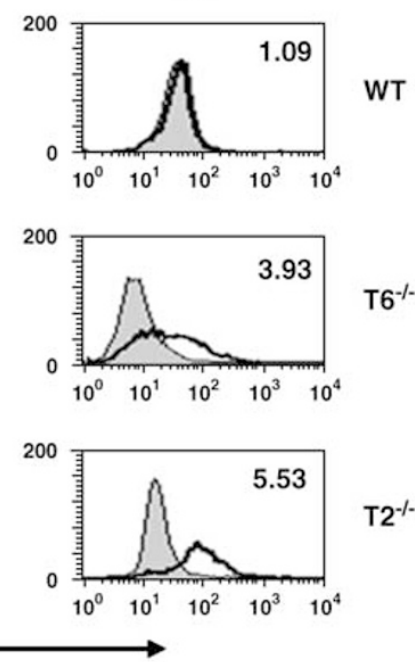
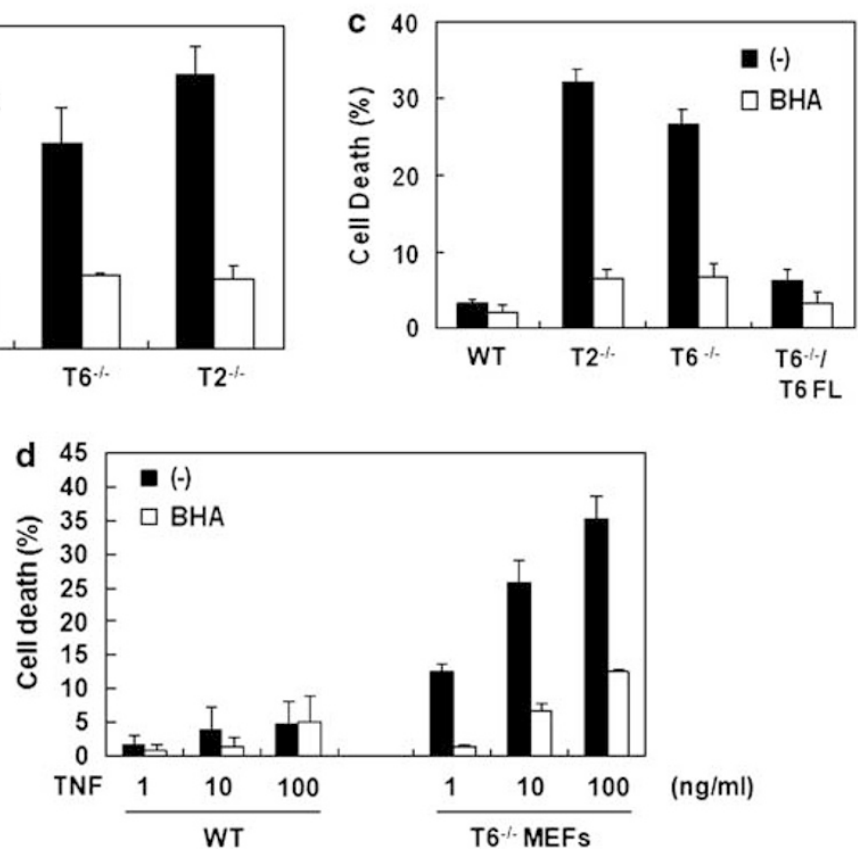

Figure 2 TNF-induced ROS accumulation in T6 ${ }^{-1-} 3$ T3 cells promotes TNF-induced cell death. (a) Cells were unstimulated (gray) or stimulated (bold line) with TNF $(30 \mathrm{ng} / \mathrm{ml})$ for the indicated times. The cells were incubated with $\mathrm{H}_{2}$ DCFDA $(2 \mu \mathrm{M})$ for 30 min prior to each time point and analyzed by flow cytometry. The ratios of mean fluorescent intensity of stimulated cells to unstimulated cells are indicated at the right upper corner. The data are representative of three independent experiments. (b) Cells were pretreated with vehicle or $\mathrm{BHA}(100 \mu \mathrm{M})$, stimulated with TNF for $4 \mathrm{~h}$, incubated with $\mathrm{H}_{2} \mathrm{DCFDA}$, and then analyzed as described in (a). (c) Cells were stimulated with TNF for $16 \mathrm{~h}$ with or without BHA $(100 \mu \mathrm{M})$ and measured for cell death as described in Figure $1 \mathrm{~b}$. (d) As in (c), except that WT and T6 ${ }^{-l-}$ MEFs were incubated with the indicated amount of TNF. The data shown are means \pm S.D. of three independent experiments

were rescued from TNF cytotoxicity (Figure 1e), suggesting that TRAF6 indeed plays a defined role of cell survival in TNF signaling. We also found that TRAF6 ${ }^{-1-}$ mouse embryonic fibroblasts (MEFs) were highly sensitive to TNF-induced cell death when compared to WT cells (Figure 1f). To further confirm the protective role of TRAF6 in other cell types, we performed a loss-of-function study in human aortic endothelial cells (HAECs) by transfection of TRAF6 small interfering RNA (siRNA). Consistently, inhibition of TRAF6 expression by siRNA significantly increased cell death after TNF stimulation (Figure 1g), indicating that TRAF6 plays a similar role in endothelial cells as it did in fibroblasts.
Recent studies have shown that ROS function as key mediators of TNF-induced cell death. ${ }^{8-10}$ We investigated whether TNF induces ROS accumulation in $\mathrm{T}^{-1-} 3 \mathrm{~T} 3$ cells. WT, $\mathrm{T6}^{-1-}$ and $\mathrm{T} 2^{-/-}$cells were stimulated with TNF for $2-8 \mathrm{~h}$, and the cells were subsequently incubated with a fluorescent dye, $\mathrm{H}_{2}$ DCFDA. As shown in Figure $2 \mathrm{a}$, fluorescent signals increased in cells lacking either TRAF2 or TRAF6, while no increase in the signal was observed in WT cells. If TNF-induced cytotoxicity is mediated by ROS in $\mathrm{T}^{-1-}$ cells, a chemical antioxidant such as butylated hydroxyanisole (BHA) may curtail the effect. As shown in Figure $2 b$, pretreatment of $\mathrm{T}^{-1-}$ 3T3 cells with BHA suppressed the accumulation of 
a

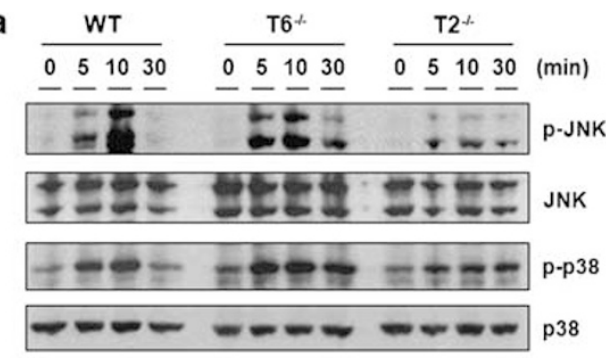

C

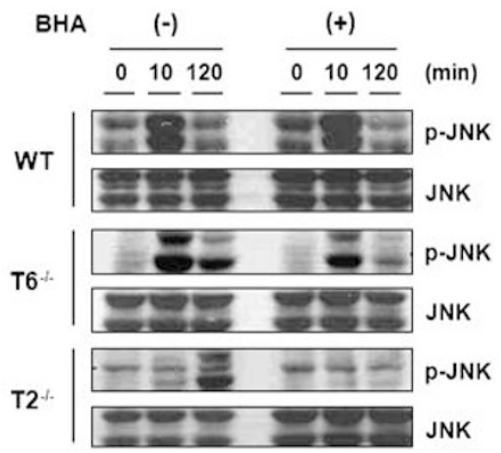

b

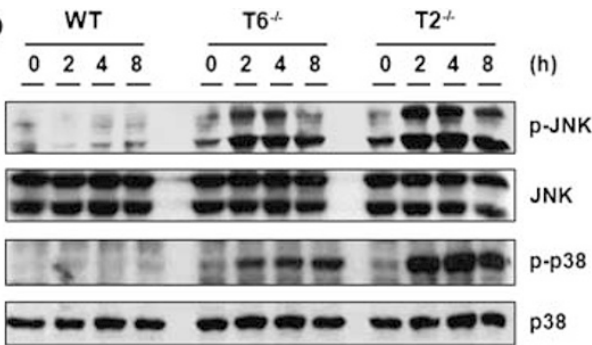

d
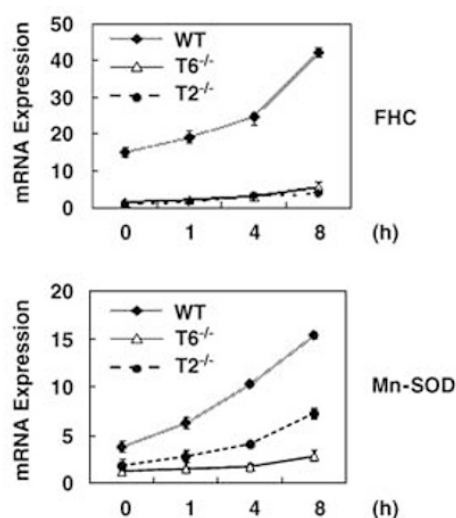

Figure 3 TNF induces ROS-dependent prolonged JNK activation in T6 ${ }^{-1-} 3 \mathrm{~T} 3$ cells. (a) WT, $\mathrm{T}^{-1-}$ and $\mathrm{T}^{-1-} 3 \mathrm{~T} 3$ cells were stimulated with TNF ( $30 \mathrm{ng} / \mathrm{ml}$ ) for the indicated times. The cell lysates were analyzed by western blotting using the indicated phosphorylated antibodies. The membranes were reblotted with antibodies to total JNK or p38 as controls. (b) As in (a), except that cells were stimulated for longer periods of time as indicated. (c) Cells were stimulated with TNF in the absence or presence of BHA $(100 \mu \mathrm{M})$ for the indicated times. The cell lysates were analyzed as in (a). (d) FHC and Mn-SOD mRNA expression levels were examined by real-time PCR analysis. The mRNA expression levels were normalized to $18 \mathrm{~S}$ rRNA. The data indicate means \pm S.D. of triplicate samples of one representative experiment out of three independent experiments

ROS. Furthermore, BHA significantly reduced the cell death in both $\mathrm{T}^{-/-} 3 \mathrm{~T} 3$ cells (Figure $2 \mathrm{c}$ ) and $\mathrm{T6}^{-/-}$MEFs (Figure $2 \mathrm{~d}$ ), indicating that TNF-induced ROS accumulation is responsible for the cell death.

TRAF6 deficiency leads to sustained JNK activation through ROS. The rapid and transient JNK activation mediated by TNF does not normally cause cell death. ${ }^{21}$ However, if the activity of JNK is changed from transient to persistent, cell death usually follows. ${ }^{7}$ In fact, in the absence of NF- $\kappa$ B activity, TNF-induced ROS production causes prolonged JNK1 activation which in turn leads to cell death. ${ }^{8,10}$ Thus, we investigated whether TNF-stimulated ROS accumulation induces prolonged MAP kinase activation in $\mathrm{T6}^{-1-}$ cells. Consistent with previous reports, ${ }^{6,20}$ phosphorylation of $\mathrm{JNK}$ at $10 \mathrm{~min}$ was severely impaired in $\mathrm{T}^{-1-}$ cells compared to that in WT and $\mathrm{T6}^{-1-}$ cells (Figure 3a). After cells were exposed to TNF for 2-8h, activation of JNK1 was sustained in both $\mathrm{T}^{-/-}$and $\mathrm{T} 2^{-1-}$ cells (Figure $3 b$ ). Similar to this finding, we also observed that siRNA to TRAF6 prolonged JNK1 activation in endothelial cells (Supplementary Figure 2). As shown in Figure 3c, an antioxidant, BHA almost completely inhibited sustained JNK activation at $2 \mathrm{~h}$ in $\mathrm{T} 6^{-1-}$ and $\mathrm{T} 2^{-1-}$ cells. As expected, BHA only slightly inhibited JNK activation at $10 \mathrm{~min}$ upon TNF stimulation in $\mathrm{T6}^{-/-}$cells.

We also examined the mRNA expression level of genes, which have recently been shown to be involved in disposal of $\mathrm{ROS}^{10,22}$ or in antiapoptotic reaction. Ferritin heavy chain
$(\mathrm{FHC})$ is the primary iron sequester that counteracts the formation of hydroxyl radical $(\mathrm{OH}),{ }^{22}$ and $\mathrm{Mn}^{++}$superoxide dismutase (Mn-SOD) is a mitochondrial enzyme that catalyzes dismutation of superoxide anion $\left(\mathrm{O}_{2}^{-}\right)$into hydrogen peroxide $\left(\mathrm{H}_{2} \mathrm{O}_{2}\right)$. These two important genes of cellular antioxidants were highly upregulated by TNF through NF- $\kappa \mathrm{B}$ activation. ${ }^{10,22}$ As shown in Figure $3 d$, their basal expression levels as well as induction levels were markedly reduced in $\mathrm{T}^{-/-}$or $\mathrm{T} 2^{-/-}$cells, indicating that the machineries such as $\mathrm{FHC}$ and $\mathrm{Mn}-\mathrm{SOD}$ to maintain cellular ROS levels are compromised in the mutant 3T3 cells.

NF- $\kappa$ B transactivation was impaired in $\mathrm{T}^{-1-}$ 3T3 cells. Given that the induction of $\mathrm{FHC}$ or ${\mathrm{Mn}-\mathrm{SOD}^{10,22} \text { was }}^{10}$ abolished in $\mathrm{T}^{-1-}$ cells (Figure $3 \mathrm{~d}$ ), we next investigated whether the loss of TRAF6 results in a defect in TNF-induced $N F-\kappa \mathrm{B}$ activation pathway. There was no difference in $\mathrm{I} \kappa \mathrm{B} \alpha$ phosphorylation and degradation (Figure 4a). Moreover, after the treatment with TNF, most p65/RelA was normally translocated into the nucleus in $\mathrm{T}^{-1-}$ cells (Supplementary Figure 3). Consistent with previous reports, ${ }^{6,23}$ TNF-induced p65/RelA translocation was not impaired in $\mathrm{T}^{-1-}$ cells either (Supplementary Figure 3). Intriguingly, p65/RelA phosphorylation was impaired in $\mathrm{T}^{-/-}$cells and even more severely so in $\mathrm{T}^{-1-}$ cells (Figure $4 \mathrm{~b}$ ). As expected, $\mathrm{T}^{-/-}$ cells reconstituted with TRAF6 showed a normal level of p65/ RelA phosphorylation upon TNF exposure (Supplementary Figure 4). It was previously shown that DNA-binding activity of p65/RelA was slightly reduced and delayed in fibroblasts 
a

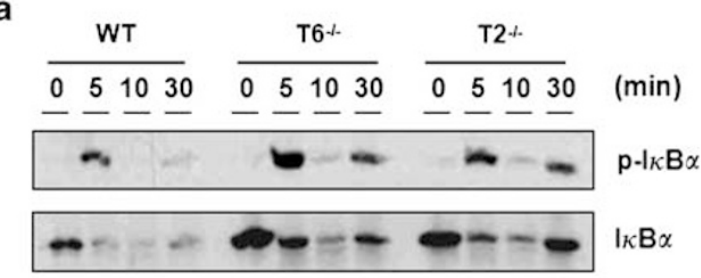

C

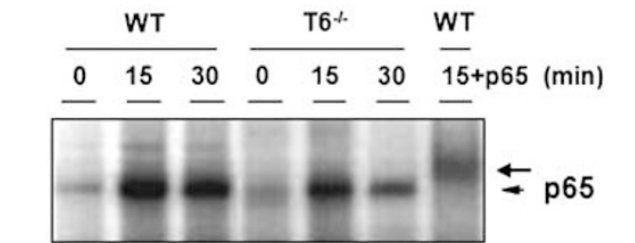

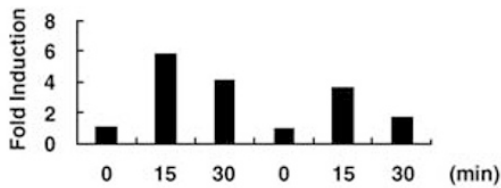

b
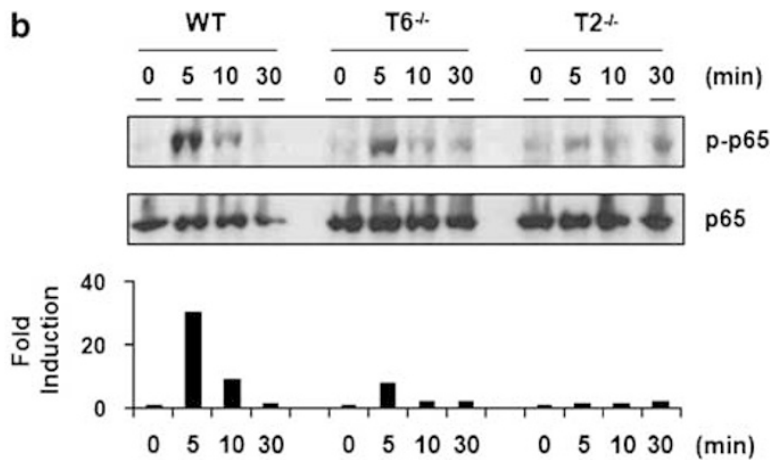

d

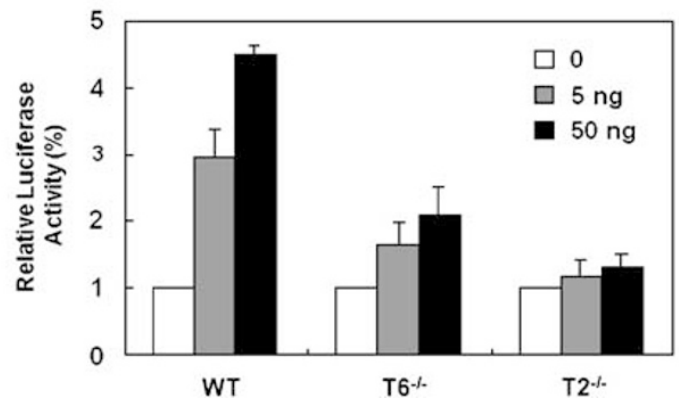

Figure 4 Impaired TNF-induced NF- $\kappa$ B activation in T6 $6^{-1-} 3 \mathrm{~T} 3$ cells. (a) The $3 \mathrm{~T} 3$ cells from WT, $\mathrm{T}^{-/-}$and $\mathrm{T} 2^{-1-}$ backgrounds were stimulated with TNF ( $\left.30 \mathrm{ng} / \mathrm{ml}\right)$ for the indicated times. The western blots show phosphorylation of $I_{\kappa} \mathrm{B} \alpha\left(\right.$ phospho- $\left.I_{\kappa} \mathrm{B} \alpha\right)$ and degradation of $I_{\kappa} \mathrm{B} \alpha$. (b) As in (a), except that p65/RelA phosphorylation was determined by phospho-p65 (Ser536) antibody and reblotted with antibody to p65/RelA as a control. The fold increase in the stimulated cells compared to untreated cells is shown. (c) Nuclear extracts $(5 \mu \mathrm{g})$ were prepared from WT and T6 ${ }^{-1-}$ fibroblasts stimulated TNF for the indicated times and examined by electrophoretic mobility shift assay as described in Materials and Methods. To control for loading amounts of nuclear extracts, levels of a constitutive nuclear protein Ref- 1 in the samples were compared by western blotting. The activated NF- $\kappa$ B complexes are indicated by the arrow. The fold increase in the stimulated cells compared to untreated cells is shown. (d) $3 T 3$ cells from WT, $\mathrm{T}^{-l-}$ and $\mathrm{T}^{-l-}$ were transiently transfected with $(\kappa \mathrm{B})_{3}$-interferon luciferase reporter and CMV- $\beta$-galactosidase plasmid. At $36 \mathrm{~h}$ after transfection, cells were treated with varying levels of TNF for $6 \mathrm{~h}$. Luciferase activity was then measured as described in Materials and Methods. The result shown is the mean of relative luciferase activity \pm S.D. of at least three independent experiments, each in duplicate

from TRAF2 knockout mice and in thymocytes from transgenic mice expressing a dominant-negative form of TRAF2 $^{6,20}$ In contrast, T6 $^{-1-}$ cells showed no significant decrease in DNA binding of NF- $\kappa$ B after TNF stimulation (Figure 4c). A previous study also showed that TRAF6 is not essential for DNA binding of NF- $\kappa$ B in response to TNF. ${ }^{18}$

We next examined NF- $\kappa$ B-dependent gene expression by a reporter assay. After $6 \mathrm{~h}$ stimulation with TNF, the luciferase activity driven by NF- $\kappa$ B promoter was significantly reduced in $\mathrm{T}^{-1-}$ cells compared to that in WT cells (Figure 4d). Therefore, TNF failed to a significant extent to stimulate the NF- $\kappa \mathrm{B}$ activation in $\mathrm{T} 6^{-1-}$ cells, revealing that TRAF6 is required for this process.

TRAF6 is involved in cell survival through modulating GSK3 $\beta$ activity. It has been reported that fibroblasts lacking glycogen synthase kinase $3 \beta$ (GSK3 $\beta$ ), a kinase previously not thought to be involved in TNF signaling, show reduced NF- $\kappa$ B-dependent transcription. ${ }^{24}$ However, that no defects in degradation of $\mathrm{I} \kappa \mathrm{B} \alpha$ or nuclear translocation of p65 were seen in GSK3 $\beta$ knockout cells, suggesting an important role of this kinase in p65/RelA transactivation by TNF. ${ }^{25,26}$ Since the regulatory role of TRAF 6 in TNF signaling appears to be similar to that of GSK3 $\beta$, we examined the possibility that loss of TRAF6 affects GSK3 $\beta$ activity. We first assessed the time course of Ser9 phosphorylation of GSK3 $\beta$, which results in inhibition of GSK3 $\beta$ activity in response to TNF. Following TNF stimulation, phosphorylation of GSK3 $\beta$ at $5 \mathrm{~min}$ increased and then gradually declined (Figure 5a). Interestingly, we found that in the absence of exogenous TNF there was a higher basal level of Ser9 phosphorylation of GSK3 $\beta$ in $\mathrm{T}^{-1-}$ cells compared to $\mathrm{T} 2^{-1-}$ or WT cells. Consistent with this finding, TRAF6-knockdown endothelial cells (Figure $5 \mathrm{~b}$ ) or T6 ${ }^{-1-}$ MEFs (Supplementary Figure 5) also showed a higher basal level of GSK3 $\beta$ phosphorylation. We also evaluated the level and duration of TNF-induced GSK3 $\beta$ phosphorylation in $\mathrm{T}^{-/-}$cells and found that GSK3 $\beta$ shows a higher and longer lasting phosphorylation than the WT cells (Figure $5 c$ ).

To verify that loss of TRAF6 influences abnormal hyperphosphorylation of GSK3 $\beta$, TRAF6 gene was stably overexpressed in $\mathrm{T6}^{-1-}$ cells. As shown in Figure $5 \mathrm{~d}$, GSK3 $\beta$ phosphorylation level was reduced by ectopic expression of TRAF6 protein. Taken together, these results suggest that TRAF6 deficiency leads to constitutive hyperinactivation of GSK3 $\beta$, which may exhibit a similar phenotype to GSK3 $\beta$-null cells.

To determine whether the inactivation of GSK3 $\beta$ is responsible for the sensitivity to TNF stimulation observed in $\mathrm{T}^{-1-}$ cells, we tested if overexpression of the constitutively active form of GSK3 $\beta$ (GSK3 $\beta$-S9A: 9th serine switched to alanine) renders $\mathrm{T}^{-1-}$ cells resistant to TNF. As 

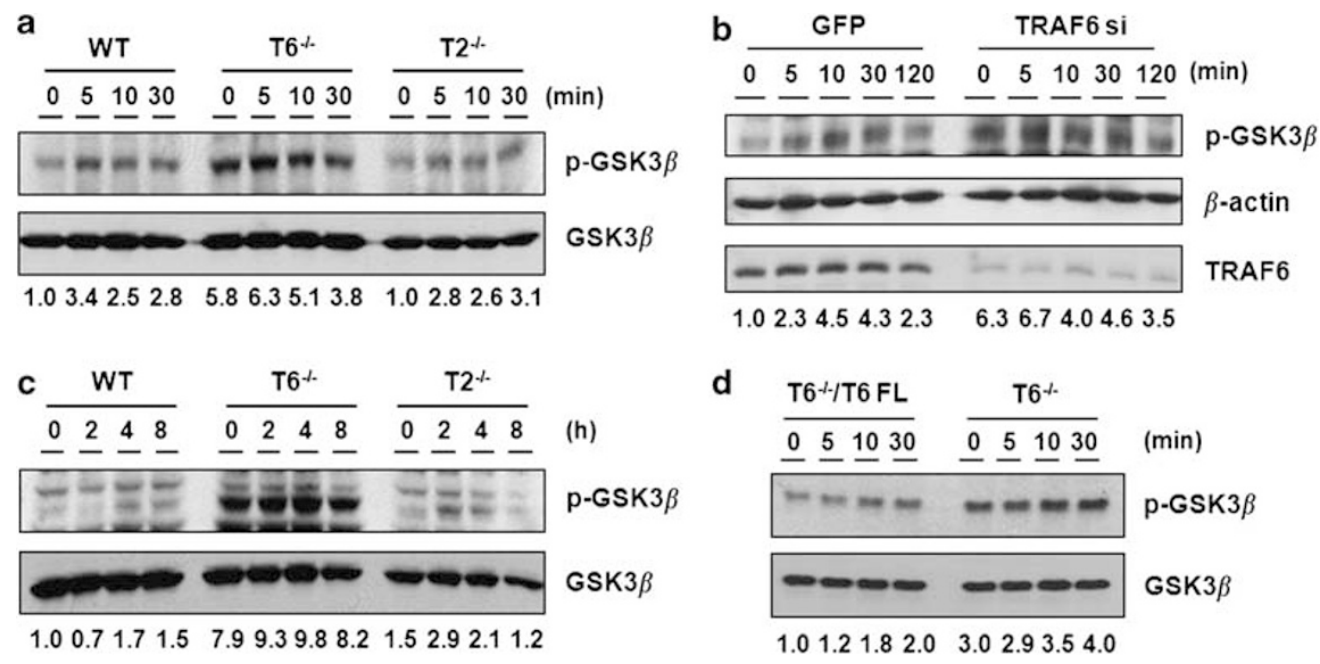

Figure 5 TRAF6 deficiency leads to hyperphosphorylation of GSK3 $\beta$. (a) WT, T6 $6^{-l-}$ and T2 $2^{-1-} 3$ T3 cells were stimulated with TNF ( $30 \mathrm{ng} / \mathrm{ml}$ ) for the indicated times. Phosphorylation levels of GSK3 $\beta$ (phospho-GSK3 $\beta$ ) were determined by immunoblotting. The membranes were reblotted with antibodies to GSK3 $\beta$ as controls. (b) As in (a), except that HAECs were transfected with TRAF6 siRNA or control siRNA and then treated with TNF for the indicated times. (c) As in (a), except for the indicated times. (d) As in (a), except for stimulating $\mathrm{T}^{-1-}$ 3T3 stably overexpressing ectopic Flag-TRAF6 with $\mathrm{T}^{-1-} 3 \mathrm{~T} 3$ cells as the control

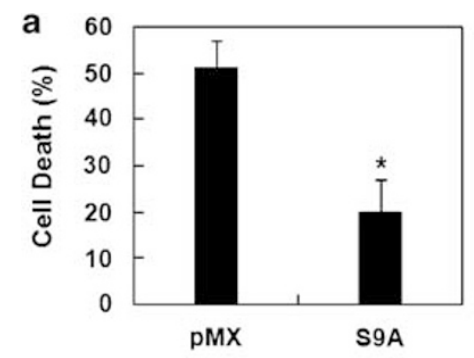

b
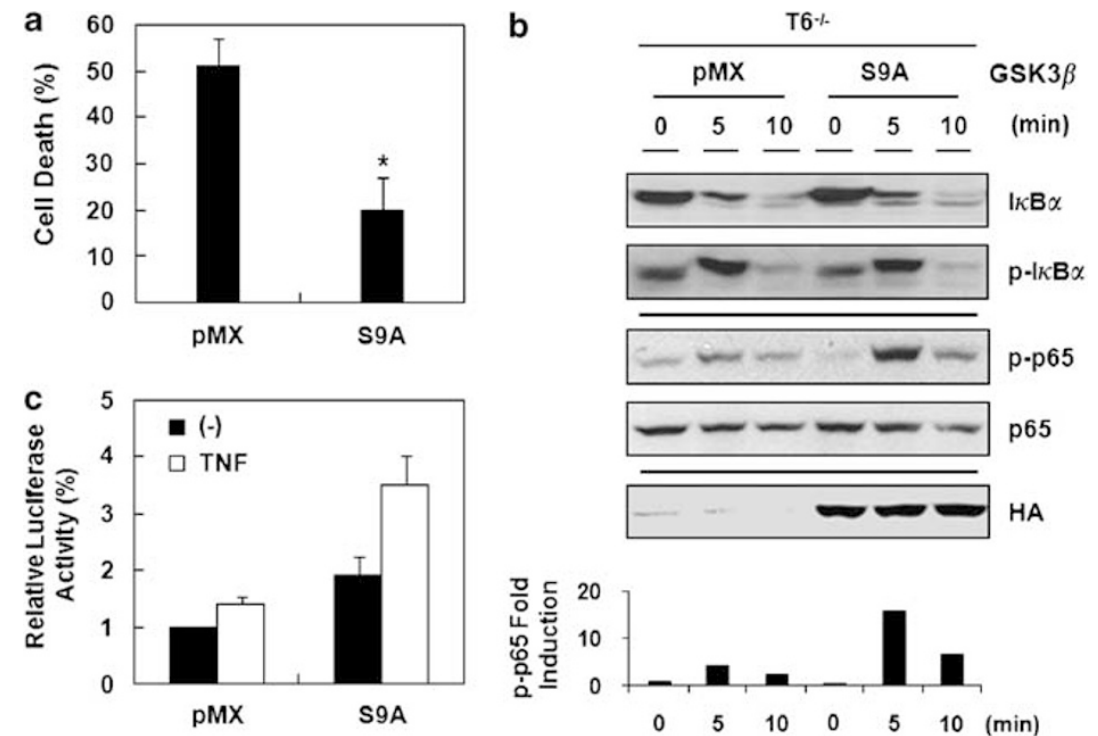

Figure 6 Rescue of cell death in T6 ${ }^{-1-} 3$ T3 cells by a constitutively active form of GSK3 $\beta$. (a) 3T3 T6 ${ }^{-1-}$ and T6 ${ }^{-1-}$ cells stably expressing HA-GSK3 $\beta$-S9A were exposed to TNF $(20 \mathrm{ng} / \mathrm{ml})$ for $16 \mathrm{~h}$. The percentages of surviving cells in PI nuclear stain were analyzed by flow cytometry. (b) Cells were exposed to TNF (20 ng/ml) for the indicated times. Phosphorylation of $I_{\kappa} \mathrm{B} \alpha$ (phospho-I $\kappa \mathrm{B} \alpha$ ), degradation of $\mathrm{I}_{\kappa} \mathrm{B} \alpha$, and $\mathrm{p} 65 /$ RelA phosphorylation (phoshpo-p65) were detected by western blot analysis and reblotted with antibody to $\mathrm{p} 65 /$ RelA as a control. The fold increase indicates phosphorylation levels of phospho-p65 in each stimulated cells compared to untreated cells. (c) NF- $\kappa$ B luciferase activity was measured as Figure 4 d. These results (a, c) shown are the mean \pm S.D. of at least three independent experiments. ${ }^{\star} P<0.05$ versus pMX-puroexpressed $\mathrm{T}^{-1-} 3 \mathrm{~T} 3$ cells

shown in Figure 6a, expression of GSK3 $\beta$-S9A substantially reduced the number of dead cells among TRAF6-null cells after TNF treatment. Next, we examined whether expression of GSK3 $\beta$-S9A rescues $\mathrm{T}^{-1-}$ cells from the defect of TNF-mediated NF- $\kappa \mathrm{B}$ activity. In the reconstituted $\mathrm{T6}^{-1-}$ cells, p65 phosphorylation and transactivation were recovered by GSK3 $\beta$-S9A (Figure $6 b$ and $c$ ), whereas $I_{\kappa} \mathrm{B} \alpha$ phosphorylation and degradation remained unaffected (Figure 6b). It is well established that IL-1 signaling also leads to the activation of NF- $\kappa \mathrm{B} .{ }^{16}$ Since
TRAF6 is crucial in IL-1-mediated NF- $\kappa$ B activation, ${ }^{18}$ it would be interesting to see whether GSK3 $\beta$-S9A rescues TRAF6 deficiency in IL-1 signaling. As expected, $\mathrm{IL}-1$-induced $\mathrm{I} \kappa \mathrm{B} \alpha$ phosphorylation and degradation were severely impaired in $\mathrm{T6}^{-/-}$cells compared to WT cells (Supplementary Figure 6). Importantly, we observed similar defects in $\mathrm{T6}^{-/-}$cells expressing GSK3 $\beta$-S9A stimulated by IL- 1 , indicating that GSK3 $\beta$ is not required for IL-1-induced signaling but rather specific to the TNF signaling pathway. 
Collectively, these results show that TRAF6 acts as a positive regulator of cell survival in TNF signaling and that such a role of TRAF 6 is mediated by modulating GSK3 $\beta$ activity.

\section{Discussion}

In the present study, we have examined the involvement of TRAF6 in the regulation of TNF-induced responses and identified TRAF6 as an intrinsic mediator of the NF- $\kappa$ B activity against TNF-induced cell death. TRAF6-mediated suppression of cell death involves inhibition of ROS accumulation, which in turn prevents sustained activation of the JNK pathway. Interestingly, in TRAF6-null 3T3 cells, we found strikingly enhanced phosphorylation of GSK3 $\beta$. Finally, overexpression of the constitutively active form of GSK3 $\beta$ restores $\mathrm{NF}-\kappa \mathrm{B}$-dependent transcriptional activity and prevents TNF-induced cell death in TRAF6-null 3T3 cells.

Although TRAF2 has been mainly recognized as a physical link between TNFR1 signaling complex and the $I_{\kappa} \mathrm{B}$ kinase (IKK) complex, ${ }^{2,3}$ mice deficient in TRAF2 or mice expressing a dominant-negative form of TRAF2 did not show substantial defects in TNF-induced NF- $\kappa$ B activation. ${ }^{6,20}$ This implies that other TRAF family protein(s) plays a redundant role in TNFinduced NF- $\kappa$ B activation. Recently, it has been shown that TRAF5 in addition to TRAF2 is involved in TNF-induced $N F-\kappa B$ activation and protection from cell death. ${ }^{23}$ However, significant levels of TNF-induced NF- $\kappa \mathrm{B}$ activity were observed in TRAF2 and TRAF5 double knockout mice, ${ }^{23}$ suggesting that yet another TRAF family member(s) may also be involved in mediating NF- $\kappa \mathrm{B}$ activation. In this respect, even though TRAF6 has not been thought to be a component of the TNFR1 complexes, the possibility that TRAF6 may contribute TNF signaling pathway through its interaction with TRAF2 cannot be excluded. In fact, a weak interaction between TRAF2 and TRAF6 has been reported from studies based on yeast two-hybrid analyses ${ }^{27}$ and a coimmunoprecipitation experiment. ${ }^{28}$

It is also possible that TRAF2 and TRAF6 play a cooperative role for the optimal induction of $\mathrm{NF}-\kappa \mathrm{B}$ activity or activate distinct sets of NF- $\kappa \mathrm{B}$ target genes. Recent evidences from biochemical and genetic experiments strongly suggest an essential role of p65/RelA phosphorylation in $\mathrm{NF}-\kappa \mathrm{B}$ activation. ${ }^{25,26}$ In this context, it has been reported that TNF-induced IKK phosphorylation of p65/RelA is mediated through the TRAF2/TRAF5-dependent pathway. ${ }^{29}$ Our results demonstrate that GSK3 $\beta$, downstream of TRAF6, targets p65/RelA for phosphorylation which enhances $\mathrm{NF}-\kappa \mathrm{B}$ transactivation potential. In other words, although TRAF2-IKK pathway mainly contributes TNF-induced NF- $\kappa \mathrm{B}$ activation, TRAF6-GSK3 $\beta$ cascade is, in part, required for an optimal NF- $\kappa$ B activation.

Alternatively, TRAF6 may activate NF- $\kappa$ B pathways independent of TRAF2. Cells lacking TRAF2 and TRAF6 exhibit similar phenotypes, including enhanced sensitivity to TNF and ROS accumulation, the latter of which results in prolonged JNK activation and cell death. Nevertheless, our studies have shown that GSK3 $\beta$ phosphorylation was dramatically increased in $\mathrm{T}^{-1-}$ cells but not in WT or $\mathrm{T}^{-1-}$ cells. This

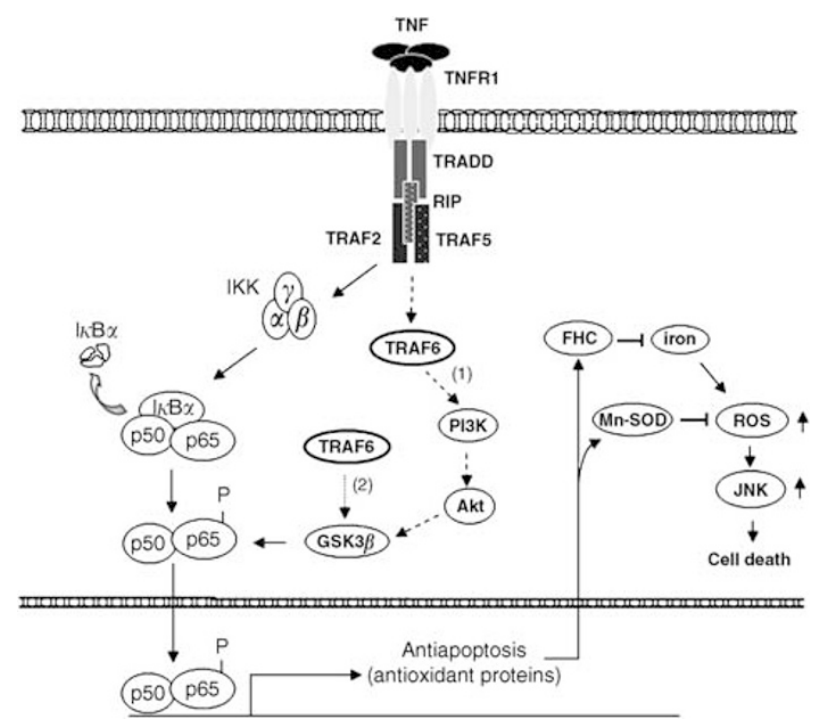

Figure 7 A proposed model for the role of TRAF6 in TNF signaling. TRAF2/ TRAF5-dependent pathway plays a major role in TNF-induced NF- $\kappa B$ activation. We propose that TRAF6 may partly contribute to the activation of NF- $\kappa B$ via PI3KAkt-GSK3 $\beta$ cascade (1). Alternatively, TRAF6 may regulate GSK3 $\beta$ by unknown mechanism(s) independent of TNF (2). In either of the cases, if TRAF6 is deficient in cells, the proper activation of NF- $\kappa$ B in response to TNF is abrogated due to GSK3 $\beta$ inactivation, eventually leading to cell death through ROS-JNK-dependent cascade

suggests that TRAF6 regulates a distinct NF- $\kappa$ B activation pathway involving GSK3 $\beta$ unlike TRAF2.

GSK3 $\beta$ is a ubiquitously expressed serine-threonine protein kinase that was originally identified as a regulator of glycogen synthase. ${ }^{30}$ GSK3 $\beta$ is also a key component of the Wnt signaling that is known to play important roles in developmental processes, including cell-fate determination. ${ }^{31} \mathrm{How}$ ever, gene targeting of GSK3 $\beta$ showed no clear phenotypes in early embryonic development. ${ }^{24}$ Surprisingly, GSK3 $\beta$ deficiency leads to enhanced TNF-induced cell death. There were no defects in degradation of $\mathrm{I} \kappa \mathrm{B} \alpha$ or nuclear translocation of p65/RelA in fibroblasts lacking GSK3 $\beta$, but NF- $\kappa$ B-dependent transcription activity was diminished. ${ }^{24}$ Such changes are similar to what was seen in TRAF6 ${ }^{-/-} 3$ T3 cells.

What is the underlying mechanism of controlling GSK $3 \beta$ via TRAF6? The PI3K-Akt pathway, upstream of GSK3 $\beta$, has been reported to function in the activation of $\mathrm{NF}-\kappa \mathrm{B}$ and cell survival. ${ }^{32-34}$ As described above, however, GSK3 $\beta$ knockout or treatment with a specific inhibitor such as lithium chloride, which should mimic the phosphorylation and inactivation of GSK3 $\beta$, resulted in cell death upon TNF stimulation. ${ }^{24,35}$ In other words, GSK3 $\beta$ phosphorylation represents an activity of PI3K-Akt opposite to its established prosurvival role. It can be speculated that TRAF6 may modulate the PI3K-Akt pathway which in turn regulates GSK3 $\beta$ activity (Figure 7) in a more elaborate manner. Proper activation of PI3K-Akt may cause partial inactivation of GSK3 $\beta$ which somehow activates NF- $\kappa$ B. In contrast, hyperactivation of PI3K-Akt causes complete block of GSK3 $\beta$ activation, which mimics GSK3 $\beta$ deficiency. There might be such a threshold that the extent of GSK3 $\beta$ inactivation decides to switch cell survival to cell death upon TNF stimulation. This scenario is supported by the finding that the extent of PI3K-Akt activation and subsequent inhibition 
of GSK3 $\beta$ regulate the decision between proinflammatory and anti-inflammatory responses in TLR signaling. ${ }^{36,37}$ More recently, specific deletion of TRAF 6 in T cells was shown to enhance the activity of PI3K-Akt signaling pathway, which implicates TRAF6 as a T-cell-intrinsic negative regulator required for the maintenance of immune homeostasis. ${ }^{38}$ In addition, we cannot exclude the possibility that TRAF6 might not play a direct role in TNF signaling. One possible scenario is that $\mathrm{GSK} 3 \beta$ activity might be constitutively kept under control by TRAF6 to favor cell survival independent of TNF (Figure 7). In this case, if TRAF6 is deficient, GSK3 $\beta$ enters a hyperphosphorylated state, thereby becoming more susceptible to TNF. The precise molecular mechanism of the linkage between TRAF6 and PI3K-Akt and/or GSK3 $\beta$ cascades requires further investigations.

In summary, our study demonstrates a novel role of TRAF6 in positively regulating the activation of $\mathrm{NF}-\kappa \mathrm{B}$ via GSK3 $\beta$. These findings further advance the understanding of the balance between cell survival and death mediated by TNF signaling.

\section{Materials and Methods \\ Cell culture and retrovirus infection. $3 \mathrm{~T} 3$ cells from WT, TRAF2 ${ }^{-1-}$, and TRAF6 $^{-1-}$ mice, which were established in culture from E14. 5 embryos using a standard 3 T 3 protocol, ${ }^{39}$ and primary MEFs from WT or TRAF6-deficient mice were maintained under standard conditions (Dulbecco's modified Eagle's medium (DMEM); Gibco, Grand Island, NY, USA, 10\% fetal bovine serum (Hyclone, Logan, UT, USA), $100 \mathrm{U} / \mathrm{ml}$ streptomycin, and $100 \mathrm{U} / \mathrm{ml}$ penicillin (Gibco) at $37 \mathrm{C}, 5 \% \mathrm{CO}_{2}$ ). HAECs were purchased from Cambrex (Walkersville, MD, USA) and were cultured in endothelial growth medium (EGM2) supplemented with $2 \% \mathrm{FBS}, 50 \mu \mathrm{g}$ gentamicin sulfate, ascorbic acid, heparin, VEGF, hEGF, hFGF-B, R3-IGF-1 and hydrocortisone (Lonza, Walkersville, MD, USA) at $37^{\circ} \mathrm{C}$ under $5 \% \mathrm{CO}_{2}$. For production of retroviral particles. Plat-E cells were cultured in DMEM containing $10 \mu \mathrm{g} / \mathrm{ml}$ blasticidin (Invitrogen, Carlsbad, CA, USA) and $1 \mu \mathrm{g} / \mathrm{ml}$ puromycin (Sigma, St Louis, MO, USA). Plat-E cells were transfected with pMX-puro empty, pMX-puro- TRAF6 or pMX-GSK3 $\beta$ S9A expression vector using FuGENE 6 (Roche, Nutley, $\mathrm{NJ}$, USA). After $48 \mathrm{~h}$, viral supernatants were collected for infection of $\mathrm{T6}^{-1-} 3 \mathrm{~T} 3$ cells with polybrene $(10 \mu \mathrm{g} / \mathrm{ml}$; Sigma). Puromycin-resistant transfectants were selected and maintained in DMEM with puromycin $(3 \mu \mathrm{g} / \mathrm{ml})$.}

Reagents and antibodies. Recombinant murine TNF was purchased from R\&D Systems (Minneapolis, MN, USA). Antibodies to phosphorylated JNK (Thr183/ Tyr185), phosphorylated p38 (Thr180/Tyr182), phosphorylated $1 \kappa \mathrm{B} \alpha$ (Ser32/36), phosphorylated p65/RelA (Ser536), phosphorylated GSK3 $\beta$ (Ser9), JNK, p38 $I_{\kappa} \mathrm{B} \alpha$, GSK $3 \beta$, and caspase 3 were purchased from Cell Signaling (Danvers, MA, USA). Antibodies specific for p65/RelA, TRAF6, and TRAF2 were purchased from Santa Cruz Biotechnology (Santa Cruz, CA, USA) Antibodies to $\beta$-actin and FLAG (M2) were purchased from Sigma and hemagglutinin (HA) from Roche Applied Science.

Western blot analysis. After stimulation with recombinant murine TNF, cells were lysed in $1 \%$ Nonidet P-40 lysis buffer (50 mM HEPES, pH 7.4, $150 \mathrm{mM} \mathrm{NaCl}$, $2 \mathrm{mM}$ EDTA, $1 \%$ Nonidet P-40, and protease inhibitors). The cell lysates were resolved by SDS-PAGE and analyzed by western blotting with specific antibodies.

Cell death assay. After treatment with TNF alone $(30 \mathrm{ng} / \mathrm{ml})$ or TNF in combination with cycloheximide (Sigma) for indicated time periods, cells were harvested, stained with propidium iodide (Sigma), and analyzed by a flow cytometer (FACSCalibur; BD Biosciences, San Jose, CA, USA).

Determination of intracellular ROS production. ROS accumulation was detected as described elsewhere., ${ }^{8,22}$ Briefly, cells were seeded at a density of $2 \times 10^{5}$ on a $35-\mathrm{cm}$ dish and stimulated with TNF in phenol red-free media. After stimulation with TNF alone $(30 \mathrm{ng} / \mathrm{ml})$ or TNF in combination with butylated hydroxyanisole (BHA; Sigma), cells were incubated with $1 \mu \mathrm{M}$ of $2^{\prime}, 7^{\prime}$ dichlorodihydrofluorescein diacetate $\left(\mathrm{H}_{2} \mathrm{DCFDA}\right.$; Molecular Probes, Eugene, OR,
USA) for 30 min prior to harvest. Cells were then assessed by flow cytometry using the CELLQuest program (BD Biosciences).

Quantitative real-time-PCR analysis. Expression levels of mouse FHC and Mn-SOD were determined by quantitative real-time (RT)-PCR using predesigned gene-specific TaqMan PCR probe and primers purchased from Applied Biosystems. Eukaryotic 18S rRNA (Applied Biosystems, Foster City, CA, USA) was used for normalization. PCR was performed using the TaqMan universal PCR master mix. Signal detection of cDNA amplification was assessed by an Applied Biosystems 7000 Sequence Detection System (ABI Prism 7000 SDS Software v1.1)

Electrophoretic mobility shift assay. Preparation of nuclear extracts from stimulated or unstimulated cells by TNF was described previously. ${ }^{20}$ The nuclear extracts were incubated with $2 \mu \mathrm{g}$ of poly $\mathrm{dl}-\mathrm{dC}$ for $10 \mathrm{~min}$, and labeled double-stranded oligonucleotide probe was then added for $30 \mathrm{~min}$ at room temperature. The reactions were analyzed by electrophoresis on $5 \%$ nondenaturing polyacrylamide gel followed by autoradiography. Double-stranded, NF- $\kappa$ B-specific oligonucleotide probe containing the two tandemly repeated NF- $\kappa \mathrm{B}$ binding sites (5'-TTGTTACAAGGGACTTTCCGCTGGGGACTTTCCAGGGAGGC GTGG-3') was used. For the supershift assay, the nuclear extracts were incubated with p65/RelA-specific antibody for $30 \mathrm{~min}$ before addition of the labeled probe.

Luciferase assay. Cells $\left(3 \times 10^{5}\right.$ cells per well) were plated onto a six-well plate 1 day prior to transfection. Lipofectamine 2000 (Invitrogen) was used as the transfection agent following the manufacturer's instructions. Each transfection was carried out using an equal amount of total DNA by adding appropriate amount of the control vector, pcDNA3.1 (Invitrogen). After $36 \mathrm{~h}$, the cells were exposed to TNF for $6 \mathrm{~h}$ before harvest. The whole-cell extracts were then prepared for the luciferase assay. The luciferase activity was measured using the Luciferase Assay System (Promega, Madison, WI, USA) and normalized relative to $\beta$-galactosidase activity as described previously. ${ }^{20}$ The data are obtained from three independent experiments and presented as the fold increase in luciferase activities (means \pm S.D.) relative to the control.

RNA interference. siRNA duplexes specific to human TRAF6 (CCACGAAGAGAUAAUGGAUdTdT and the complementary oligonucleotide) were synthesized by BIONEER (Dajeon, Korea). The nonspecific siRNA duplex derived from green fluorescent protein (GFP) was used as a control. HAECs were transiently transfected with TRAF6 siRNA or GFP siRNA duplexes using Oligofectamine ${ }^{\mathrm{TM}}$ reagent following the manufacturer's instruction (Invitrogen).

Data analysis. Data are presented as means plus or minus S.D.s from at least three independent experiments. Statistical significance was determined using oneway analysis of variance followed by the Student's $t$-test. The phosphorylation of GSK 3 or p65 was determined using the software, Science Lab Image Gauge V4.0 (Fujifilm).

Acknowledgements. We thank Dr. Wen-Chen Yeh for providing TRAF2deficient 3 T3 cells, Matthew C. Walsh for providing TRAF6-/- MEFs, Dr. Toshio Kitamura for providing the Plat-E cell line, and Dr. Hong-Duk Um for providing Ref-1 antibody. This work was supported in part by the KOSEF grant M1-0641-35-0002 (SYL), by the Korea Research Foundation Grant funded by the Korean Government (MOEHRD) (KRF-2006-C00309), and by NCRC program of MOST/KOSEF (Grant no. R15-2006-020-00000-0) through the Center for Cell Signaling \& Drug Discovery Research at Ewha Womans University. KY was supported by BK21 fellowship.

Conflict of interest disclosure: The authors declare no competing financial interests.

1. Aggarwal BB. Signalling pathways of the TNF superfamily: a double-edged sword. Nat Rev Immunol 2003; 3: 745-756.

2. Locksley RM, Killeen N, Lenardo MJ. The TNF and TNF receptor superfamilies: integrating mammalian biology. Cell 2001; 104: 487-501.

3. Chen G, Goeddel DV. TNF-R1 signaling: a beautiful pathway. Science 2002; 296: 1634-1635.

4. Hsu H, Huang J, Shu HB, Baichwal V, Goeddel DV. TNF-dependent recruitment of the protein kinase RIP to the TNF receptor-1 signaling complex. Immunity 1996; 4: 387-396.

5. Hsu H, Shu HB, Pan MG, Goeddel DV. TRADD-TRAF2 and TRADD-FADD interactions define two distinct TNF receptor 1 signal transduction pathways. Cell 1996; 84: 299-308. 
6. Yeh WC, Shahinian A, Speiser D, Kraunus J, Billia F, Wakeham A et al. Early lethality, functional NF- $\kappa$ B activation, and increased sensitivity to TNF-induced cell death in TRAF2deficient mice. Immunity 1997; 7: 715-725.

7. Deng $Y$, Ren $X$, Yang L, Lin $Y$, Wu X. A JNK-dependent pathway is required for TNF $\alpha$-induced apoptosis. Cell 2003; 115: 61-70.

8. Sakon S, Xue X, Takekawa M, Sasazuki T, Okazaki T, Kojima $Y$ et al. NF- $\kappa$ B inhibits TNF-induced accumulation of ROS that mediate prolonged MAPK activation and necrotic cell death. EMBO J 2003; 22: 3898-3909.

9. Bubici C, Papa S, Dean K, Franzoso G. Mutual cross-talk between reactive oxygen species and nuclear factor- $\kappa B$ : molecular basis and biological significance. Oncogene 2006; 25 6731-6748.

10. Kamata $\mathrm{H}$, Honda $\mathrm{S}$, Maeda $\mathrm{S}$, Chang L, Hirata $\mathrm{H}$, Karin M. Reactive oxygen species promote TNF $\alpha$-induced death and sustained JNK activation by inhibiting MAP kinase phosphatases. Cell 2005; 120: 649-661.

11. Arch RH, Gedrich RW, Thompson $\mathrm{CB}$. Tumor necrosis factor receptor-associated factors (TRAFs) - a family of adapter proteins that regulates life and death. Genes Dev 1998; 12 : 2821-2830.

12. Bradley JR, Pober JS. Tumor necrosis factor receptor-associated factors (TRAFs). Oncogene 2001; 20: 6482-6491.

13. Ichijo H, Nishida $\mathrm{E}$, Irie $\mathrm{K}$, ten Dijke $\mathrm{P}$, Saitoh M, Moriguchi T et al. Induction of apoptosis by ASK1, a mammalian MAPKKK that activates SAPK/JNK and p38 signaling pathways. Science 1997; 275: 90-94

14. Regnier $\mathrm{CH}$, Song HY, Gao X, Goeddel DV, Cao Z, Rothe M. Identification and characterization of an $I_{\kappa} B$ kinase. Cell 1997; 90: 373-383.

15. Xu LG, Li LY, Shu HB. TRAF7 potentiates MEKK3-induced AP1 and CHOP activation and induces apoptosis. J Biol Chem 2004; 279: 17278-17282.

16. Wu H, Arron JR. TRAF6, a molecular bridge spanning adaptive immunity, innate immunity and osteoimmunology. Bioessays 2003; 25: 1096-1105.

17. Barton GM, Medzhitov R. Toll-like receptor signaling pathways. Science 2003; 300: 1524 1525.

18. Lomaga MA, Yeh WC, Sarosi I, Duncan GS, Furlonger C, Ho A et al. TRAF6 deficiency results in osteopetrosis and defective interleukin-1, CD40, and LPS signaling. Genes Dev 1999; 13: 1015-1024.

19. Ichikawa D, Funakoshi-Tago M, Aizu-Yokota E, Sonoda Y, Inoue J, Kasahara T. TNFreceptor associated factor 6 -deficient fibroblast is sensitive to the TNF- $\alpha$-induced cell death: involvement of reactive oxygen species. Biochem Biophys Res Commun 2006; 351 93-98.

20. Lee SY, Reichlin A, Santana A, Sokol KA, Nussenzweig MC, Choi Y. TRAF2 is essential for JNK but not NF- $\kappa \mathrm{B}$ activation and regulates lymphocyte proliferation and survival. Immunity 1997; 7: 703-713.

21. Nakano H, Nakajima A, Sakon-Komazawa S, Piao JH, Xue X, Okumura K. Reactive oxygen species mediate crosstalk between NF- $\kappa$ B and JNK. Cell Death Differ 2006; 13: 730-737.
22. Pham CG, Bubici C, Zazzeroni F, Papa S, Jones J, Alvarez $\mathrm{K}$ et al. Ferritin heavy chain upregulation by NF- $\kappa$ B inhibits TNF $\alpha$-induced apoptosis by suppressing reactive oxygen species. Cell 2004; 119: 529-542.

23. Tada K, Okazaki T, Sakon S, Kobarai T, Kurosawa K, Yamaoka S et al. Critical roles of TRAF2 and TRAF5 in tumor necrosis factor-induced NF- $\kappa$ B activation and protection from cell death. J Biol Chem 2001; 276: 36530-36534.

24. Hoeflich KP, Luo J, Rubie EA, Tsao MS, Jin O, Woodgett JR. Requirement for glycogen synthase kinase- $3 \beta$ in cell survival and NF- $\kappa$ B activation. Nature 2000; 406: 86-90.

25. Viatour P, Merville MP, Bours V, Chariot A. Phosphorylation of NF- $\kappa \mathrm{B}$ and $I_{\kappa} \mathrm{B}$ proteins: implications in cancer and inflammation. Trends Biochem Sci 2005; 30: 43-52.

26. Schmitz ML, Mattioli I, Buss $\mathrm{H}$, Kracht M. NF- $\kappa$ B: a multifaceted transcription factor regulated at several levels. Chem Bio Chem 2004; 5: 1348-1358.

27. Nguyen LT, Duncan GS, Mirtsos C, Ng M, Speiser DE, Shahinian A et al. TRAF2 deficiency results in hyperactivity of certain TNFR1 signals and impairment of CD40-mediated responses. Immunity 1999; 11: 379-389.

28. Davies CC, Mak TW, Young LS, Eliopoulos AG. TRAF6 is required for TRAF2-dependent CD40 signal transduction in nonhemopoietic cells. Mol Cell Biol 2005; 25: 9806-9819.

29. Sakurai H, Suzuki S, Kawasaki N, Nakano H, Okazaki T, Chino A, Doi T, Saiki I. TNFainduced IKK phosphorylation of NF- $\kappa \mathrm{B}$ p65 on serine 536 is mediated through TRAF2, TRAF5, and TAK1 signaling pathway. J Biol Chem 2003; 278: 36916-36923.

30. Frame $S$, Cohen P. GSK3 takes centre stage more 20 years after its discovery. Biochem $J$ 2001; 359: 1-16.

31. Woodgett JR. Judging a protein by more than its name: GSK-3. Sci STKE 2001; 2001: RE12.

32. Ozes ON, Mayo LD, Gustin JA, Pfeffer SR, Pfeffer LM, Donner DB. NF- $\kappa$ B activation by tumour necrosis factor requires the Akt serine-threonine kinase. Nature 1999; 401 $82-85$

33. Kane LP, Shapiro VS, Stokoe D, Weiss A. Induction of NF- $\kappa$ B by the Akt/PKB kinase. Curr Biol 1999; 9: 601-604

34. Downward J. PI 3-kinase, Akt and cell survival. Semin Cell Dev Biol 2004; 15: 177-182.

35. Schwabe RF, Brenner DA. Role of glycogen synthase kinase-3 in TNF- $\alpha$-induced NF- $\kappa B$ activation and apoptosis in hepatocytes. Am J Physiol Gastrointest Liver Physiol 2002; 283 G204-G211.

36. Woodgett JR, Ohashi PS. GSK3: an in-Toll-erant protein kinase? Nat Immunol 2005; 6 751-752

37. Martin M, Rehani K, Jope RS, Michalek SM. Toll-like receptor-mediated cytokine production is differentially regulated by glycogen synthase kinase 3. Nat Immunol 2005; 6 : 777-784.

38. King CG, Kobayashi T, Cejas PJ, Kim T, Yoon K, Kim GK et al. TRAF6 is a T cell-intrinsic negative regulator required for the maintenance of immune homeostasis. Nat Med 2006; 12: $1088-1092$

39. Todaro GJ, Green H. Quantitative studies of the growth of mouse embryo cells in culture and their development into established lines. J Cell Biol 1963; 17: 299-313.

\section{Supplementary Information accompanies the paper on Cell Death and Differentiation website (http://www.nature.com/cdd)}

